\title{
Weights in Multidimensional Indices of Well-Being: An Overview*
}

\author{
Koen Decancq ${ }^{\dagger}$ \\ María Ana Lugo $\ddagger$ \\ Revised version
}

March 4, 2010

\begin{abstract}
Multidimensional indices are becoming increasingly important instruments to assess the well-being of societies. They move beyond the focus on a single indicator and yet, are easy to present and communicate. A crucial step in the construction of a multidimensional index of well-being is the selection of the relative weights for the different dimensions. The aim of this paper is to study the role of these weights and to critically survey eight different approaches to set them. We categorize the approaches in three classes: data-driven, normative and hybrid weighting, and compare their respective advantages and drawbacks.
\end{abstract}

Keywords: composite indicator, multidimensional well-being index, weights.

JEL Classification: I31, C43, O1.

\footnotetext{
*We thank Sabina Alkire, Tony Atkinson, Laurens Cherchye, Francisco Ferreira, Alessio Fusco, Marc Fleurbaey, James E. Foster, Nicky Rogge, Luc Van Ootegem, Elsy Verhofstadt, as well as participants at the OPHI workshop on Weighting Dimensions (2008). We also received valuable comments and remarks on this or a previous version of the paper at the AEA (2009) conference in San Francisco and the HDR 2010 consultation in Rabat. María Ana Lugo thanks the UK Economic and Social Research Council for financial support. The usual disclaimer applies.

${ }^{\dagger}$ Koen Decancq: Center for Economic Studies, Katholieke Universiteit Leuven, Naamsestraat 69, B3000 Leuven, Belgium and CORE, Université catholique de Louvain, B-1348 Louvain-la-Neuve, Belgium. E-mail: koen.decancq@econ.kuleuven.be.

${ }^{\ddagger}$ María Ana Lugo: Department of Economics, University of Oxford, Manor Road Building, Manor Road, OX1 3UQ, Oxford, UK. E-mail: maria.lugo@economics.oxford.ac.uk.
} 
"Since any choice of weights should be open to questioning and debating in public discussions, it is crucial that the judgments that are implicit

in such weighting be made as clear and comprehensible as possible and thus be open to public scrutiny." (Anand and Sen 1997, p. 6)

\section{Introduction}

Rooted in a tradition going back to Aristotle, philosophers such as Rawls (1971), Sen (1985, 2009) and Nussbaum (2000) have advocated a multidimensional perspective on the notion of well-being. They argue that focussing on a sole indicator of well-being - often income - leads to a narrow-sided perspective and that it remains blind to important sources of heterogeneity between individuals. The idea that well-being is inherently multidimensioned has by now become well-established in the academic and policy-oriented literature. ${ }^{1}$ In a large-scale survey among the global poor carried out by the World Bank, it is documented that the poor themselves also conceive well-being and deprivation as multifaceted notions, with both material and psychological dimensions (Narayan 2000). Also, the rapidly emerging literature on the determinants of happiness and life satisfaction shows that people's overall satisfaction is affected by many aspects of life, such as their health, employment, material resources and marital status (Kahneman and Krueger 2006).

Recently, many proposals have been made to operationalize this multidimensional perspective by making use of a single index of well-being. Such an index aggregates the many achievements of an individual (for instance, her material standard of living, her health, her educational outcomes and her political freedoms). Well-being indices, also known as composite indicators of well-being or indices of quality of life, allow us to compare all individuals in a society with respect to their well-being, and across time and space. The use of such an index moves the focus beyond the sole focus on one indicator and yet, its results are easy to present and communicate. Therein lie its main advantages. Well-being indices can be seen as useful tools for governments and analysts to readily obtain a picture of the distribution of the well-being in a society. As such, they have the

\footnotetext{
${ }^{1}$ In a recent report of the Commission on the Measurement of Economic Performance and Social Progress, chaired by Nobel prize laureates Stiglitz and Sen (2009), the authors write "To define what well-being means, a multidimensional definition has to be used. Based on academic research and a number of concrete initiatives developed around the world, the Commission has identified the following key dimensions that should be taken into account. At least in principle, these dimensions should be considered simultaneously: (i) Material living standards (income, consumption and wealth); (ii) Health; (iii) Education; (iv) Personal activities including work $(v)$ Political voice and governance; (vi) Social connections and relationships; (vii) Environment (present and future conditions); (viii) Insecurity, of an economic as well as a physical nature. All these dimensions shape people's well-being, and yet many of them are missed by conventional income measures.".

The European Commission gives an overview of well-being indices used by national and international institutions on http://composite-indicators.jrc.ec.europa.eu/.
} 
increasingly important role of complementing (rather than replacing) other commonly used measures, such as GDP per capita or life expectancy. ${ }^{2}$

There exists a plethora of multidimensional well-being indices. They differ in the dimensions and indicators selected, the transformations applied to the indicators, the assumed substitutability between indicators and the relative weights given to them. Rawls (1971, p.80) refers to the problem of selecting an appropriate well-being index as the index problem. A crucial role in this problem, he explains, is played by the relative weights of the dimensions. As we argue in this paper, weights are central in determining of the trade-offs between the dimensions of well-being. Weights are also crucial in choosing the list of candidate dimensions, by assigning a positive value to some dimensions and zero to those left out. In that sense, they reflect particular value judgements on how a 'good life' should look like. This makes the problem of selecting the appropriate weighting scheme, one with clear normative implications. Our aim here is to make these normative implications explicit, while studying the specific role of the weights. We will critically survey eight different approaches taken in the literature to set the weights - See Table 1.

Table 1: Approaches to set the weights

\begin{tabular}{l|l|l}
\hline Data-driven & Hybrid & Normative \\
\hline \hline 1. frequency & 7. self-stated & 4. equal or arbitrary \\
2. statistical & 8. hedonic & 5. expert opinion \\
3. most-favorable & & 6. price based \\
\hline
\end{tabular}

We distinguish three important classes of approaches to set the weights: datadriven, normative and hybrid. Data-driven weights are a function of the distribution of the achievements in the society and are not based, at least explicitly, on any value judgement about how the trade-offs between the dimensions should be. Normative approaches, on the other hand, only depend on the value judgements about the trade-offs and are not based on the actual distribution of the achievements in the society under analysis. Hybrid approaches are both data-driven and depend on some form of valuation of these achievements.

The distinction between data-driven and normative approaches echoes the philosophical is-ought distinction, introduced by the 18th century philosopher David Hume. Hume noted that many claims about what 'ought to be' are actually based on statements about what 'is'. However, according to Hume, there is a significant difference between descriptive statements (about what is) and normative statements (about what ought to be). He not only distinguishes between 'is' and 'ought', between facts and values, he argues, furthermore, that it is impossible to derive an 'ought' from an 'is' (Hume 1740).

\footnotetext{
${ }^{2}$ We refer the reader to Micklewright (2001) for a detailed treatment of advantages and disadvantages of using a multidimensional well-being index.
} 
The impossibility to derive a statement about values from a statement about facts also known as Hume's guillotine - has been eloquently formulated by Popper (1948) as follows:

"Perhaps the simplest and most important point about ethics is purely logical. I mean the impossibility to derive nontautological ethical rules imperatives; principles of policy; aims; or however we may describe them from statements of facts." (Popper 1948, p.154)

Hume's guillotine raises a fundamental problem for the data-driven approaches that aim at retrieving the weights from the distribution of the achievements alone. The content of a 'good life' is indeed a matter of values, which can, according to Hume, not be derived from the factual distribution of the achievement vectors. Normative approaches, on the other hand, rely only on value judgements to set the weights and, hence, escape Hume's guillotine. However, normative approaches have their own fundamental problem: Whose value judgements on the 'good life' are reflected in the weights? Indeed, it is well-documented that there is much interpersonal variation in opinions on the 'good life' (Schokkaert 2007). In other words, the individuals in a society are very likely to disagree on the most appropriate weights for the dimensions of well-being. Kenneth Arrow (1950) showed in his celebrated impossibility theorem that it is impossible to aggregate the different individual value judgements into a society-wide one, while also meeting a certain set of reasonable criteria. The well-being of some individuals will inevitably be judged based on a well-being index, which reflects value judgements which are not their own. Hence, normative approaches obviously suffer from some form of paternalism.

Setting the weights in a multidimensional analysis seems to become a problem of choosing between Scylla and Charybdis, between Hume's guillotine and paternalism. Some recent proposals explore the narrow and dangerous strait of Messina between Scylla and Charybdis, as Odysseus did when returning from Troy. These are the hybrid approaches, which combine information on the actual distribution of the achievements with individual valuations of these achievements. This is accomplished by either asking the individuals explicitly about their own valuation or by inferring their valuation from their general level of happiness. One may argue that such a hybrid approach risks suffering from both Hume's guillotine and paternalism. A less risky solution is the one followed by Aeneas who avoided the deadly strait altogether. A researcher can avoid Hume's guillotine and the problem of paternalism in the indexing problem by selecting wide ranges of acceptable weights rather than only one weighting scheme and, hence, by refraining from the construction of one single well-being index. The inevitable price is the incompleteness of the ranking of the individuals; some individuals can be ranked, but others can not. Foster and Sen (1997, p. 206) state that while "the possibility of arriving at a unique set of weights is rather unlikely, that uniqueness is not really necessary to make 
agreed judgements in many situations."

The paper is structured as follows. In the second section we present a flexible wellbeing index. We show that the index is sufficiently general to contain many of the recently proposed multidimensional indices of well-being as special cases. Using this flexible index, in section three we elaborate on the interpretation of the weights and their role in the determination of the trade-offs between the dimensions of well-being. In section four, we classify eight different approaches to set the weights into three classes (see table 1) and critically survey them, highlighting some of their advantages and drawbacks. Section five investigates other approaches taken that allow looking beyond a unique weighting scheme and which generally lead to incomplete orderings. Section six concludes.

\section{Measuring well-being: a unifying framework}

Let us assume that there are $m$ dimensions of well-being that are relevant for the assessment of persons' well-being and, moreover, that the achievement in all of these dimensions can be measured in an interpersonal comparable way. Some standard dimensions considered include income - as command over resources -, health, education, and employment status.

Let $x_{j}^{i}$ denote the non-negative achievement of individual (or country) $i$ in dimension $j$ and let the achievement vector $x^{i}=\left(x_{1}^{i}, \ldots, x_{m}^{i}\right)$ summarize these achievements across all $m$ dimensions for individual $i .^{3}$ The distribution matrix $X=\left(x^{1}, \ldots, x^{n}\right)^{\prime}$ collects the achievement vectors of the $n$ individuals in the society. For notational convenience, we drop the index $i$ whenever the identification of individual $i$ is not necessary. The indexing problem can be described as the search for an appropriate well-being index $I($.$) ,$ that maps any achievement vector $x$ on the real line, so that they can be ranked naturally. In the present paper we confine ourselves to the following flexible index of well-being,

$$
I(x)= \begin{cases}{\left[w_{1} I_{1}\left(x_{1}\right)^{\beta}+\ldots+w_{m} I_{m}\left(x_{m}\right)^{\beta}\right]^{1 / \beta}} & \text { for } \beta \neq 0 \\ I_{1}\left(x_{1}\right)^{w_{1}} * \ldots * I_{m}\left(x_{m}\right)^{w_{m}} & \text { for } \beta=0 .\end{cases}
$$

The well-being index is defined as a weighted mean of order $\beta$ of the transformed achievements $I_{j}\left(x_{j}\right) .{ }^{4}$ The dimension-weights $w_{1}, \ldots, w_{m}$ are all non-negative and, for simplicity, are assumed to sum to one. The interpretation of these weights and how to set them is the topic of this paper. Before turning to the weights, though, we briefly

\footnotetext{
${ }^{3}$ Note that $x_{j}^{i}$ can also denote shortfall in achievement to a pre-defined threshold, and the resulting index represents the extent of multidimensional poverty. Indeed, in reviewing the literature on how to set weights (section four), we also include examples where these approaches have been used to construct multidimensional poverty indices.

${ }^{4}$ Blackorby and Donaldson (1982) provide an axiomatic characterization of the weighted mean of order $\beta$. In the literature on multidimensional inequality, Maasoumi (1986) provides an information-theoretic justification of this class of well-being indices. Further, it belongs to the wider class of well-being indices proposed by Bourguignon (1999) while it is similar to the proposal by Foster et al (2005) for a distributionsensitive measure of human development. Decancq and Lugo (2009) axiomatically characterize it as part of a multidimensional Gini measure and Decancq et al. (2009) have used it to analyze the trend in multidimensional global inequality.
} 
discuss the other two components of the well-being index which are the transformation functions $I_{j}($.$) and the parameter \beta$.

Table 2 surveys some types of widely used transformation functions $I_{j}($.$) in the$ literature, in order of increasing generality. Common examples of a rescaling (type B) are obtained by taking the ratio of the indicator value to the mean or median of the total population. Common linear transformations (type C) are the computation of $z$-scores or the difference between the indicator value and the minimum value divided by the range, as in the Human Development Index (HDI). A popular increasing transformation (type D) is the logarithmic transformation or the use of categorical scores (one, two, three, for instance). In this paper, we do not prioritize one type of transformation method over another, but limit ourselves to presenting them while highlighting the crucial role they play in the interpretation of the dimension weights.

Table 2: Transformation functions $I_{j}($.$) .$

\begin{tabular}{|c|c|c|}
\hline type & transformation function & mathematical expression \\
\hline $\mathrm{A}$ & identity & $I_{j}\left(x_{j}\right)=x_{j}$ \\
\hline B & rescaling & $I_{j}\left(x_{j}\right)=a_{j} x_{j}$ with $a_{j}>0$ \\
\hline $\mathrm{C}$ & linear transformation & $I_{j}\left(x_{j}\right)=a_{j} x_{j}+b_{j}$ with $a_{j}>0$ \\
\hline $\mathrm{D}$ & increasing transformation & $\begin{array}{c}I_{j}\left(x_{j}\right)=\phi_{j}\left(x_{j}\right) \text { with } \phi_{j} \text { a monotone } \\
\text { increasing function }\end{array}$ \\
\hline $\mathrm{E}$ & other transformation & $I_{j}\left(x_{j}\right)=\phi_{j}\left(x_{j}\right)$ with $\phi_{j}$ any function \\
\hline
\end{tabular}

Appropriate transformation functions $I_{j}($.$) for well-being indices are generally em-$ ployed for two reasons. First, since the achievements are often measured in different measurement units - such as income in pounds and health in years -, they need to be transformed or standardized to a common basis before they can be sensibly aggregated. Transformation functions of type $\mathrm{B}$ and $\mathrm{C}$ are typically used to make the achievements scale independent. Second, if the original distribution is skewed, the transformation functions can be employed to avoid that excessive relative importance is given to outliers or extreme values. To achieve that goal, concave monotone increasing functions such as the logarithm can be very useful. ${ }^{5}$

The second component in expression (1) is the parameter $\beta$. One useful interpretation of $\beta$ is related to the elasticity of substitution between the transformed achievements, $\sigma$, where $\sigma=\frac{1}{1-\beta}$. The smaller the value of $\beta$, the smaller the allowed substitutability between dimensions, that is, the more one has to give up of one achievement to get an extra unit (of transformed achievement) of a second dimension while keeping the level of well-being constant. Generally, for $\beta<1$ the well-being index is a concave function,

\footnotetext{
${ }^{5}$ For a more extensive survey of the various transformation procedures and their properties we refer the reader to Jacobs et al. (2004) and Nardo et al. (2005).
} 
which reflects a preference for a more equal vector of (transformed) achievements.

For $\beta=1$, the weighted mean of order $\beta$ is reduced to the standard weighted arithmetic mean of the following form:

$$
I(x)=w_{1} I_{1}\left(x_{1}\right)+\ldots+w_{m} I_{m}\left(x_{m}\right) .
$$

Due to its simplicity and clarity of procedure, expression (2) is used frequently in practice to construct well-being indices. However, the consequence of setting $\beta=1 \mathrm{might}$ not always be desirable. The elasticity of substitution between transformed achievements is infinite and the dimensions are seen as perfect substitutes, meaning that there is a fixed rate at which transformed achievements can be exchanged which is constant for all possible levels of all achievements. ${ }^{6}$

By using expression (1), we assumed a common degree of substitution for all pairs of dimensions. We chose to do so for simplicity of exposition. Nonetheless, this might not always be a sensible assumption to make. There is no reason to believe that, for instance, the degree of substitutability between years of good health and years of education is exactly the same as the degree of substitutability between years of good health and income. One alternative is to use a nested approach where, first, several indicators within one dimensions are aggregated using expression (1) with each subset having a specific $\beta$ and, second, these subsets are combined using the same expression (with a different $\beta$ ). Another alternative is to allow the substitutability parameter $\beta$ to be a function of the achievements, as proposed by Bourguignon and Chakravarty (2003).

In short, the framework proposed reduces the decisions to be made to three: the value of the parameter $\beta$, the transformation functions $I_{1}(),. \ldots, I_{m}($.$) and the weights$ $w_{1}, \ldots, w_{m}$. Table 3 gives a (non-exhaustive) overview of recent studies that propose multidimensional indices of well-being and poverty, together with the respective choices on the parameters made. In some cases, the indices aggregate various indicators for each dimension with one procedure and then aggregate the dimensions with a different set of parameters - see, for instance Noble et al. (2008).

As mentioned above, the majority of the indices reviewed make use of linear transformations of the indicators and aggregate by an (un)weighted average across the indicators. Yet, there are valid reasons to contest these choices and suggest other parameter values. These choices have a non-trivial impact on the resulting ordering of achievement vectors, and should therefore be explicitly presented. ${ }^{7}$ In the next section, we go deeper into the meaning of the weights.

${ }^{6}$ Other commonly used values of $\beta$ are $\beta=0$ and $\beta \rightarrow-\infty$. The first case is favored by Ebert and Welsch (2004) when dimensions are measured in different measurement units. It implies a unit elasticity of substitution between transformed achievements, in other words, a one percent decrease in one of the dimensions can be compensated by a one percent increase in another dimension. The second case, where $\beta \rightarrow-\infty$, assumes that the elasticity of substitution is equal to zero, which means that there is no possible substitution between dimensions. In this case, the well-being index becomes the minimum of the transformed achievements across the dimensions.

7 A striking example can be found in the work by Becker, et al. (1987). The authors studied the quality of life in 329 metropolitan areas of the U.S. by ordering them according to standard variables such 
Table 3: overview literature

\begin{tabular}{|c|c|c|c|c|}
\hline authors & index name (if available) & transformation & $\beta$ & weights \\
\hline Battiston et al. (2009) & & $\mathrm{C}$ & $1,2,3$ & 5,7 \\
\hline Becker et al. (2005) & & $\mathrm{D}$ & $0^{\#}$ & 6 \\
\hline Boelhouwer (2002) & Life Conditions Index & A & 1 & $2^{\dagger}, 4^{\ddagger}$ \\
\hline Bossert et al. (2009) & & $\mathrm{D}$ & 1 & 7 \\
\hline Center for Global Development (2003 - ) & Commitment to Development Index & $\mathrm{C}$ & 1 & 4 \\
\hline Chowdurty and Squire (2006) & & $\mathrm{C}$ & 1 & 5 \\
\hline Community and Local Government (England) (2007 - ) & Index of Multiple Deprivation & $\mathrm{D}$ & 1 & $2^{\dagger}, 4^{\dagger}, 7^{\ddagger}$ \\
\hline De Kruijk and Rutten (2007) & & $\mathrm{C}$ & 1 & 7 \\
\hline Decancq et al. (2009) & & $\mathrm{C}, \mathrm{E}$ & {$[-5,1]$} & 2,4 \\
\hline Desai (1993) & Social Progress Index & $\mathrm{C}$ & 1 & 2 \\
\hline Desai and Shah (1988) & & $\mathrm{C}$ & 1 & 1 \\
\hline Despotis $(2005 b, 2005 a)$ & & $\mathrm{C}, \mathrm{D}$ & 1 & 3 \\
\hline Deutsch and Silber (2005) & & $\mathrm{E}$ & 1 & 1,4 \\
\hline Di Tommaso (2006) & & A & 1 & 2 \\
\hline Diener (1997) & Quality of Life Index & $\mathrm{C}$ & 1 & 4 \\
\hline Fleurbaey and Gaulier (2009) & & $\mathrm{D}$ & - & 6 \\
\hline Fleurbaey et al. (2009) & & $\mathrm{A}, \mathrm{E}$ & 1 & 8 \\
\hline Hallerod $(1995,1996)$ & Proportional Deprivation Index & $\mathrm{A}$ & 1 & 7 \\
\hline Hirschberg et al. (1991) & & A & 0,1 & $2^{\dagger}, 4^{\ddagger}$ \\
\hline European System of Social Indicators & Index of Individual Living Conditions & $\mathrm{E}$ & 1 & 4 \\
\hline Justino (2005) & & $\mathrm{C}, \mathrm{D}$ & $-1 / 3,-1 / 2,1$ & $4, \mathrm{~S}$ \\
\hline Klasen (2000) & & $\mathrm{E}$ & 1 & 2 \\
\hline Krishnakumar (2007) & & A & 1 & 2 \\
\hline Krishnakumar and Ballon (2008) & & A & 1 & 2 \\
\hline Lugo (2007) & & $\mathrm{C}$ & {$[-20,1]$} & 4 \\
\hline Maasoumi and Lugo (2008) & & $\mathrm{A}, \mathrm{C}$ & {$[-3,1]$} & 4 \\
\hline Maasoumi and Nickelsburg (1988) & & A & $-2,-1,-1 / 2,0$ & 2,4 \\
\hline Mahlberg and Obersteiner (2001) & & $\mathrm{C}$ & 1 & 3 \\
\hline Mascherini and Hoskins (2008) & & A & 1 & 5 \\
\hline Nilsson (2010) & & $\mathrm{C}$ & {$[-20,1]$} & 4 \\
\hline Noorbakhsh (1998) & & $\mathrm{C}$ & $-2^{\#}$ & 2 \\
\hline Osberg and Sharpe (2002) & Index of Economic Well-being & $\mathrm{C}$ & 1 & $1,4^{\dagger}, 4^{\ddagger}$ \\
\hline Ram (1982) & & A & 1 & 2 \\
\hline Ramos and Silber (2005) & & $\mathrm{S}$ & S & $1,2,3,4$ \\
\hline Save the Children (2000 - ) & Mothers' Index & $\mathrm{C}$ & 1 & 4 \\
\hline Statistics Sweden (2004) & & $\mathrm{C}$ & 1 & $\mathrm{~S}$ \\
\hline Townsend et al. (1988) & Material Deprivation Score & $\mathrm{C}$ & 1 & 4 \\
\hline UNDP $(1990$ - ) & Human Development Index & $\mathrm{C}, \mathrm{D}$ & 1 & 4 \\
\hline UNDP (1995 - ) & Gender-related Development Index & $\mathrm{C}$ & -1 & 1,4 \\
\hline UNDP (1997 - ) & Human Poverty Index - 1 & $\mathrm{~A}$ & 3 & 4 \\
\hline UNDP (1997 - ) & Human Poverty Index - 2 & $\mathrm{~A}$ & 3 & 4 \\
\hline Zaim et al. (2001) & & $\mathrm{A}$ & 1 & 3 \\
\hline Zhou et al. (2010) & & $\mathrm{A}$ & 0 & 3 \\
\hline
\end{tabular}

Legend: $1=$ frequency based; $2=$ statistical; $3=$ most favorable; $4=$ equal or arbitrary; $5=$ expert; $6=$ price based; $7=$ self stated; $8=$ hedonic; $\mathrm{A}=$ identity transformation; $\mathrm{B}=$ rescaling; $\mathrm{C}=$ linear transformation; $\mathrm{D}=$ increasing transformation; $\mathrm{E}=$ other transformation; $\mathrm{S}=$ sensitivity analysis. \# afterwards an increasing transformation of the index is applied;

$\dagger$ indicators;

$\ddagger$ dimensions. 


\section{The meaning of the weights}

In this section we follow a standard approach in microeconomics to uncover the value judgements that are implicit in the class of well-being indices introduced in the previous section. We investigate the set of achievement vectors that lead to the same well-being level and which are thus thought to reflect a life which is equally good. In particular, we study how small changes in the achievements of the different dimensions can or cannot compensate each other. We do this by analyzing the marginal rate of substitution, and by specifically looking at the role played therein by the weights. ${ }^{8}$

The marginal rate of substitution between two dimensions $-j_{1}$ and $j_{2}$ - denoted $M R S_{j_{1}, j_{2}}$ is the amount of dimension 2 an individual is willing to give up for an extra unit of dimension 1 , while maintaining the same level of well-being. ${ }^{9}$ In other words:

$$
M R S_{j_{1}, j_{2}}=\frac{\partial I(x)}{\partial x_{j_{1}}} / \frac{\partial I(x)}{\partial x_{j_{2}}} .
$$

After some elementary calculations we get the following result:

Result For all achievement vectors $x$ in $R_{+}^{m}$ and all well-being indices defined by expression (1), it holds that:

$$
M R S_{j_{1}, j_{2}}=\frac{w_{j_{1}}}{w_{j_{2}}} \frac{I_{j_{1}}^{\prime}\left(x_{j_{1}}\right)}{I_{j_{2}}^{\prime}\left(x_{j_{2}}\right)}\left[\frac{I_{j_{2}}\left(x_{j_{2}}\right)}{I_{j_{1}}\left(x_{j_{1}}\right)}\right]^{1-\beta} .
$$

The marginal rate of substitution between dimensions consists of three components. The first component of expression (3) is the ratio of the dimension-specific weights $w_{j_{1}} / w_{j_{2}}$. The larger the weight assigned to dimension $j_{1}$, the more of dimension $j_{2}$ that the person is willing to give up to compensate for the extra unit of dimension $j_{1}$. The second part of expression (3) consists of the ratio of the derivatives of the transformation functions of dimension $j_{1}$ and $j_{2}$. The steeper the transformation function of $j_{1}$ the larger the amount of dimension $j_{2}$ necessary to give away to compensate for the unit gain in $x_{j_{1}}$. Finally, the marginal rate of substitution depends on the ratio of the transformed achievements to the power $1-\beta$. For $\beta<1$, the smaller the original achievement in dimension $j_{1}$, the greater the amount forgone of dimension $j_{2}$ to compensate for the extra unit in dimension $j_{1}$. This makes sense; achievements are more valuable as they become scarcer. Indeed, it is reasonable to argue that the amount of money needed to compensate for an extra year of life should be quite different whether the person is young or at the end of a normal life. In other words, it might be desirable to allow for the rate of

as quality of climate, health, security and economical performance. The authors find that, depending on the weighting scheme chosen, there were 134 cities that could be ranked first, and 150 cities that could be rank last. Moreover, there were 59 cities that could be rated either first or last, using the same data, but by selecting alternative weighting schemes.

${ }^{8}$ See also Anand and Sen (1997) for a similar approach.

${ }^{9}$ Graphically, the $M R S_{j_{1}, j_{2}}$ reflects the slope of the iso-well-being curves in the $\left(x_{j_{1}}, x_{j_{2}}\right)$ space. 
substitution between dimensions to vary, depending on their levels, so that more income is demanded to compensate for a decrease in health at low levels of health. An even stronger claim about the rate of substitutability is made by the Human Development Report (2005).

"Progress in human development requires advances across a broad front: losses in human welfare linked to life expectancy, for example, cannot be compensated for by gains in other areas such as income or education." (United Nations Development Programme, 2005)

At the same time, however, the leading index of the Human Development Report - the Human Development Index - sets $\beta$ equal to one and, hence, assumes perfect substitutability between the transformed achievements. Indeed, in the linear case $(\beta=1)$, the trade-off is assumed constant at all levels of achievements. ${ }^{10}$

$$
M R S_{j_{1}, j_{2}}=\frac{w_{j_{1}}}{w_{j_{2}}} \frac{I_{j_{1}}^{\prime}\left(x_{j_{1}}\right)}{I_{j_{2}}^{\prime}\left(x_{j_{2}}\right)}
$$

If, in addition, the ratio of the derivatives of the transformation functions is unity, the marginal rate of substitution between two dimensions is uniquely defined by the ratio of their weights.

$$
M R S_{j_{1}, j_{2}}=\frac{w_{j_{1}}}{w_{j_{2}}}
$$

To sum up, the weights play an important role in the determination of the trade-offs between the dimensions of well-being and, hence, they implicitly imply a specific view on how the 'good life' should look like. Inherently, the choice of the most appropriate weighting scheme is one with a normative implication.

\section{Approaches to setting weights}

We survey and classify eight different approaches to set the dimension-weights $w_{1}, \ldots, w_{m}$. From the previous section it is clear that this choice is inherently connected to the choice on the other elements of the well-being index: the transformation functions $I_{1}(),. \ldots, I_{m}($.$) and degree of substitutability \beta$. In this section, we focus on the question how are dimension-weights generally specified. In addition, we believe that surveying the approaches to select weights can also be helpful when choosing the values of the other two elements mentioned above.

\footnotetext{
${ }^{10}$ Note, however, that the rate at which dimensions are traded off, measured in its original units and not transformed, is constant (though not perfect) between the pair health-education, and non constant for health-income and education-income pairs. Due to the log transformation employed to per capita GDP, the trade-off between, say, per capita GDP and life expectancy also depends on the level of income the country achieves. In particular, the amount of money required to compensate for a year more of life expectancy is increasing in income; for a rich country such as Belgium an extra year of life expectancy is valued at nearly 7,000 US \$ (in PPP terms) which for a relative poor country, such as Cote d'Ivoire this is merely 300 US\$. Therefore, contrary to the claim above, the Human Development Index does indeed allow for compensation between dimensions, even when this compensation might vary across levels.
} 
We group the eight approaches in three categories: data-driven, normative and hybrid approaches. Data-driven approaches let the data "speak for themselves" and depend solely on the distribution matrix $X$. Data-driven weights are not based on any explicit value judgement about how the trade-offs between the dimensions should be. Normative approaches, on the other hand, only depend on the value judgements on the trade-offs and are not based on the distribution matrix $X$. In other words, if one of the achievement vectors in the society changes, but the valuations of the individuals stay the same, the weights obtained by a data-driven approach will change, but the ones obtained by a normative procedure will remain unaffected. A hybrid approach combines both approaches and uses information on the value judgements together with information on the actual distribution of the achievement vectors, summarized in $X$.

\subsection{Data-driven weights}

\section{Approach 1. Frequency-based weights}

A frequency-based weight of a dimension is determined as a function of the distribution of the achievement levels in that dimension. In the context of multidimensional deprivation measurement, it is often argued that there should be a inverse relation between the frequency of deprivation in a dimension and the weight of that dimension (Deutsch and Silber 2005, p.150) -less frequent deprivations get a higher weight. This is motivated by the idea that individuals attach a higher importance to the shortfalls in dimensions where a majority do not fall short. ${ }^{11}$ A person might feel more deprived if her deprivation is shared by a minority group than if the majority were similarly deprived. These weights can be interpreted as "objective measures of the subjective feelings of deprivation" (Desai and Shah 1988, p. 512).

Along these lines, Desai and Shah (1988) set the weight of a dimension in a multidimensional poverty index as the proportion of the society that is non-deprived in that dimension. Within the fuzzy set approach to multidimensional poverty, Cerioli and Zani (1990), and Cheli and Lemmi (1995) use the normalized logarithm of the inverse of the proportion of the deprived individuals in a dimension, as the weight of that dimension.

An advantage of frequency-based weights is that it is robust against the inclusion of dimensions which are only relevant for a small minority of the population. Dimensions on which everyone scores relatively low (having caviar for breakfast, for instance) will get a small weight in the overall well-being index (Desai and Shah 1988). However, in an empirical application based on Italian data, Brandolini (2007, p. 10) finds the results based on frequency weights to be relatively unstable. Furthermore, Brandolini

\footnotetext{
${ }^{11}$ Deutsch and Silber (2005, p.150) give the following example: "if owning a refrigerator is much more common than owning a dryer, a greater weight should be given to the former indicator so that if an individual does not own a refrigerator, this rare occurrence will be taken much more into account in computing the overall degree of poverty than if some individual does not own a dryer, a case which is assumed to be more frequent."
} 
obtains marginal rates of substitution between the dimensions which he describes to be "certainly a matter of disagreement". More fundamentally, this approach hinges on the (implicit) assumption that the relative importance of the different dimensions, and hence the opinion on the 'good life', depends crucially and only on the relative deprivation levels across the different dimensions. In general, this seems a strong and rather restrictive assumption about the nature of the evaluation process about the 'good life'.

\section{Approach 2. Statistical weights}

Kirshnakumar and Nagar (2008) distinguish two broad sets of statistical approaches that are employed to select the most appropriate weighting scheme: descriptive and explanatory models.

The first approach relies on multivariate statistical methods to describe or summarize the data. The most commonly used technique is based on principal component analysis (Klasen 2000, Noorbakhsh 1998). The use of principal component analysis is often motivated by a concern for the so-called problem of double counting. In many empirical applications the indicators of well-being are found to be strongly correlated and capturing the same latent dimension. ${ }^{12}$ Loosely speaking, in principal component analysis, the set of initial indicators is transformed into an equal number of mutually uncorrelated linear combinations of indicators. One can compute the proportion of the variance explained by each of these linear combinations. Either the weights can be obtained from the linear combination that explains the largest proportion of the variance, or by using a weighted average of all the linear combinations. Boelhouwer (2002) uses a more sophisticated version of principal component analysis, called OVERALS that allows one to work with categorical indicators of the initial indicators.

The explanatory approach assumes that some observed variables (indicators) are dependent on a certain number of unobserved latent variables, called factors (Krishnakumar and Nadar 2008). Factor analysis is possibly the simplest explanatory approach, imposing that the observed indicators are, in fact, different manifestations of the same latent variable (Noble, Wright, Smith, and Dibben 2006). More complex explanatory approaches include other exogenous variables that might also influence the latent variable but are not part of the selected set of indicators used to construct the index. In the context of multidimensional poverty measurement, Fusco and Dickens (2008) use a Rasch model that allows taking the binary nature of deprivation variables into account. Further sophistication of factor analysis include multiple indicator and multiple causes models (MIMIC)

\footnotetext{
${ }^{12}$ For instance, Srinivasan (1994) reports a correlation coefficient of about 0.8 between the dimensions of the Human Development Index. Whether double counting is really a problem for constructing multidimensional indices of well-being or not is a matter open for discussion. One could argue that, indeed, the existence of correlation between the dimensions of well-being in a society reflects an important aspect of the society's situation and, as such, it should be included, and not eliminated, from the analysis. The pluralistic egalitarian notion of Walzer (1983), for instance, considers that the correlation between the dimensions is one of the essential characteristics of a society. From that perspective, correcting for correlation between the dimensions might be deemed inappropriate.
} 
and structural equation models (SEM), which have been proposed to construct multidimensional indices, particularly in the operationalization of Sen's capability approach (Kuklys 2005, Di Tommaso 2006, Krishnakumar 2007, Krishnakumar and Ballon 2008).

There are, however, some drawbacks to these multivariate statistical approaches. First, one could argue that it is usually hard to interpret the obtained linear combination of indicators as an index of human well-being (Srinivasan 1994). Nardo et al. (2005) point out that correlations do not necessarily represent the real influence of the indicators on well-being. Principal components analysis will assign lower weights to dimensions that are poorly correlated, while one could argue that a multidimensional approach is called upon precisely because important dimensions of well-being are not strongly related (Somarriba and Pena 2009). Additionally, the derivation of weights through principal component or explanatory models is not straightforward and lacks transparency, which makes this technique less attractive as a method to inform policy makers (de Kruijk and Rutten 2007). Most crucially, statistical approaches can lead to counter-intuitive weights. For instance, in the construction of the Environmental Sustainability Index, the principal component method was found to assign negative weights to some valuable dimensions (World Economic Forum 2001, p. 23). Finally, Brandolini implicitly refers to Hume's guillotine when he warns that "we should be cautious in entrusting a mathematical algorithm with a fundamentally normative task" (Brandolini 2007, p.10).

\section{Approach 3. Most favorable weights}

When applying the same weighting scheme to all individuals, some of them might feel that the evaluation of their well-being is submitted to someone else's perspective on what well-being exactly is. This critique of paternalism motivated an approach in which all individuals get the 'benefit of the doubt' by selecting, for each individual, the most favorable weighting scheme. This method is a particular case of the data envelope analysis and has originally been proposed for evaluating macro-economic performance (Melyn and Moesen 1991). Recently, it has been used in the construction of well-being indices (Mahlberg and Obersteiner 2001, Despotis 2005a, Despotis 2005b) and of deprivation (Zaim, Fare, and Grosskopf 2001). Cherchye et al. provide an overview (2007). The weights are individual-specific and endogenously determined such that they maximize the obtained well-being of the individual. ${ }^{13}$ The highest relative weights are given to those dimensions on which the individual performs best. To avoid that all the weight is given to one dimension (the best dimension of the individual), extra constraints can be imposed to the weights specifying lower bounds.

Drawbacks of this approach are the following: First, since every individual has her

\footnotetext{
${ }^{13}$ In the case that $\beta$ equals one, this problem reduces to linear programming problem. Cherchye et al. (2008) provide technical details. For $\beta$ equal to one (the multiplicative case) the same methodology can be applied after a logarithmic transformation of the data (Cherchye, Lovell, Moesen, and Van Puyenbroeck 2007, footnote 11). In a recent paper, Zhou et al. (2010) compute most favorable weights for a multiplicative well-being index.
} 
own weighting scheme, the comparison of the well-being levels across individuals is not straightforward. ${ }^{14}$ Second, the obtained results depend on the exact formulation of the constraints chosen by the analyst (such as the lower bounds on the weights), which makes the procedure less transparent and, again, makes it susceptible to the initial critique of paternalism. Finally, and most importantly, there is no guarantee that the most favorable weights lead to reasonable trade-offs between the dimensions. There seems to be no $a$ priori reason why a certain dimension on which the individual performs relatively well should have a larger impact on total well-being, because the individual performs well on that dimension. This dimension might be the easiest for the individual to achieve, but not necessarily the one she most values.

\subsection{Normative weights}

\section{Approach 4. Equal or arbitrary weights}

As it is clear from Table 3, the most commonly used approach for weighting in multidimensional indices of well-being is equal or arbitrary weighting. Equal weighting has often been defended by its simplicity or from the recognition that all indicators are equally important ${ }^{15}$ or from an agnostic viewpoint. As an example of the latter argument, Mayer and Jencks defend equal weighting by remarking that: "ideally we would have liked to weight ten hardships according to their relative importance in the eyes of legislators and the general public, but we have no reliable basis for doing this" (Mayer and Jencks 1989, p. 96).

A primal example of equal weighting is the HDI. It is argued that the main motivation for using equal weighting is to treat the three dimensions equally, because all three dimensions are deemed equally important. Yet, Ravallion (1997) looks at the implied marginal rates of substitution in the HDI and finds that: "The HDI's implicit monetary valuation of an extra year of life rises from a remarkably low level in poor countries to a very high level in rich ones. In terms of both absolute dollar values and the rate of GDP growth needed to make up for lower longevity, the construction of the HDI assumes that life is far less valuable in poor countries than in rich ones; indeed, it would be nearly impossible for a rich country to make up for even one year less of life on average through economic growth, but relatively easy for a poor country". He concludes: "The value judgements underlying these trade-offs built into the HDI are not made explicit, and they are questionable." (Ravallion 1997, p. 633).

Weights can also be set in an arbitrary, but unequal way. Researchers or policy makers may decide to give more weight to dimensions that are deemed to be more

\footnotetext{
14 Despotis (2005b) proposes a way of using the individual most favorable weights to construct a common weighting structure. This is done by minimizing the distance between the individual (country)specific weight and the global weights.

${ }^{15}$ Strictly speaking, equal weighting assigns $1 / m$ weight to all $m$ dimensions included in the well-being index and zero weight to all dimensions of well-being not included.
} 
important. An example is the educational index used as subcomponent of the HDI, giving $2 / 3$ weight to the literacy rate and $1 / 3$ to the combined gross enrolment rate. The crucial question becomes how to identify the relative importance of the different dimensions. Fleurbaey states: "One can of course invoke the ethical preferences of the observer and ask her, for instance, how she trades the suicide rate off against the literacy rate, but there is little philosophical or economic theory that gives us clues about how to form such preferences." (Fleurbaey 2009, p. 1055).

Despite its popularity, equal weighting is far from uncontroversial. Chowdhury and Squire refer to equal weighting as "obviously convenient but also universally considered to be wrong." (Chowdhury and Squire 2006, p. 762). As shown in the previous section, there is no escape from the fact that the weights reflect an important aspect of the tradeoffs between the dimensions, so that agnosticism cannot be achieved. Such as any other weighting scheme, the equal weighting scheme implies, in interplay with choices about the transformation and substitutability, specific trade-offs between the dimensions, that can and should be made explicit, and might be considered reasonable or not.

\section{Approach 5. Expert opinion weights}

To avoid the arbitrariness of following the opinions of only one researcher or policy maker on the appropriate weights, one can consult opinions of several experts or informed persons. The assumption is that consultations with a group of experts can provide "a more systematic representation of the diversity of expert judgement that is typically provided in every experts meeting. ... [and] ... a clear indication of the nature and the extent of agreement within the scientific community" (Mascherini and Hoskins 2008, p. 4).

There are two typical methods to elicit views from experts. The first is the Budget Allocation technique. Experts are asked to distribute a budget of points to a number of dimensions, paying more for those dimensions whose importance they want to stress. Mascherini and Hoskins (2008) question 27 experts from various fields (sociologists, political scientists, policy makers and educationalists) on the importance of the dimensions to construct the Active Citizen Composite Indicator, put forward by the European Commission. The results from the questionnaires show the different views on the importance of each dimension of the indicator. The final weights were obtained computing the median of the distribution of responses (standardized to sum to 100). Another example is brought by Moldan and Billharz (1997) who report a case study in which 400 German experts from very different social backgrounds were asked to allocate a budget to a set of environmental indicators related to air pollution, leading to very consistent results. A related approach is used by Chowdury and Squire (2006), who use electronic surveys to elicit weighting schemes from the 'expert community', which is understood as development researchers throughout the world. The authors ask participants to weight 
each component of the HDI on a scale from zero to ten. Interestingly enough, they find that the average weighting scheme does not statistically differ from the present equal weighting scheme used in the index.

The second method is the Analytic Hierarchy Process. This method has been proposed by Saaty (1987) and originates from multi-attribute decision making. All members of the representative group are asked to compare pairs of dimensions by asking the question: "Which of the two is more important? - and by how much?". The strength of the preference is expressed on a semantic scale. These comparisons result in a comparison matrix from which the relative weights can be calculated using an eigenvector technique (see Nardo et al. (2005) and the references therein for a detailed treatment).

The main source of concern with the expert opinion weights relates to the selection of the experts. The selection may be biased - some groups being under-represented - or simply uninformed, resulting in a skewed weighting scheme. A second concern is that, even when the selection is bias-free, the expert opinion weights may be unrepresentative for the total population under analysis. In that case, the approach leads to some sort of paternalism since they rely on imposing some people's ideas on the importance of each dimension to other individuals.

\section{Approach 6. Price based weights}

In the previous section, we showed that the weights are an important constitutive element of the implied marginal rates of substitution between the dimensions of wellbeing. From this insight, appropriate weights can be derived once the marginal rates of substitution are known and some assumptions are made on the transformation functions and degree of substitutability. For some commonly used dimensions of well-being, such as health and education, specific studies have computed the marginal rates of substitution with income, hence, their implicit prices. For instance, Murphy and Topel (2006) survey the literature on the 'value of health and longevity' and a long tradition in economics of education, pioneered by Psacharopoulos, estimates the monetary returns to schooling (Card 1999).

Although such a price-based approach has been suggested by Srinivasan (1994), it seems not to be very popular in the literature on multidimensional well-being indices. Notable exceptions are Becker et al. (2005) using the 'value of life' literature to calibrate their full-income concept, and Fleurbaey and Gaulier (2009) who extend the approach further by incorporating dimensions such as risk of unemployment, healthy life expectancy, and household demography. However, Foster and Sen (1997) argue that even if implicit prices can be obtained, they are in general "inappropriate for well-being comparisons, a task for which they are not constructed." (Foster and Sen 1997). 


\subsection{Hybrid weights}

\section{Approach 7. Stated preference weights}

Instead of imposing trade-offs chosen by a set of experts, stated preference weights are based directly on the opinions of (a representative group of) individuals in the society. In that sense it is both a data-driven approach and one that depends on the valuation of the individuals themselves.

Survey-based approaches to weighting dimensions are relatively new to economists, but have a long pedigree in the sociological literature on poverty and deprivation. Mack and Lansley (1985) propose a 'direct consensual definition of poverty' in terms of 'an enforced lack of socially perceived necessities'. To identify the socially perceived necessities, respondents were asked to list the consumption items that they thought all adults should be able to afford. ${ }^{16}$ According to Mack and Lansley an item supported by at least half of the society constitutes a socially perceived necessity. Halleröd $(1995,1996)$ uses the proportion of the population that regards an item as a necessity to obtain the respective weight for the construction of what he labelled the 'proportional deprivation index'. He stresses that the weight assigned to each consumption item is not connected to a subjective evaluation of a particular individual or household but to the average evaluation in the society (Halleröd 1996, p. 150).

Only recently are similar approaches being used by economists in multidimensional analyses of poverty. De Kruijk and Rutten (2007) use the Maldivean household survey in which (randomly sampled) respondents are asked to rank dimensions according to their relative importance in determining the overall standard of living. For each individual, the weight for a dimension is computed as a function of the total number of dimensions and the specific ranking of that dimension. Finally, the paper uses the average weight across individuals to compute the individual specific 'human vulnerability index'. A second series of examples of stated preference weights are based on European data sets. The annually collected EU-SILC data set contains various monetary and non-monetary indicators of poverty and deprivation (such as monetary resources, possession of durables, and characteristics of housing). Interestingly, the special 2007 Eurobarometer survey on the perception of poverty and social exclusion asked respondents to evaluate the necessity of the same set of indicators. Guio et al. (2009) compare multivariate poverty indices based on various weighting schemes, including stated preference weights. These weights are obtained as the proportion of respondents that consider an item (absolutely) necessary. The authors find a limited impact of alternative weighting schemes on the ranking of countries. A similar approach has been followed by Bossert et al. (2009) using

\footnotetext{
${ }^{16}$ One may be concerned that respondents do not take a sufficiently 'publicly-oriented' point of view when considering minimal standards of living, but rather that they are influenced by their own possessions. Using a data set for Belgium, Van den Bosch (1998) studies the relation between the individual possessions and perceptions of necessity and finds that respondents can reasonably well distinguish between what they themselves have and what should be considered a necessity for others.
} 
a slightly different list of items.

By collecting additional information on the individual valuations of the dimensions, stated preference weights avoid Hume's guillotine. Unfortunately, in most data sets questions to derive individual valuations are not available, limiting the extent of application of this approach. Yet, as these data become more widely available, one can imagine that stated-preference weights become a method of choice for many.

\section{Approach 8. Hedonic weights}

The idea of this approach is to retrieve information about the implicit valuation of well-being by the individual through information about her self-reported happiness or life satisfaction. Schokkaert (2007), for instance, proposes to rely on the emerging measures and data sets on self-reported life satisfaction. The weights can be derived from a (usually linear) regression of life satisfaction on a set of variables representing the different dimensions of well-being (see also, Nardo et al. (2005) for a similar approach). If $Y^{i}$ is a measure of life satisfaction of individual $i$, the weights can be obtained from the estimated coefficients of $\alpha_{1}, \ldots, \alpha_{m}$ from the following regression model:

$$
Y^{i}=\alpha_{1} I_{1}\left(x_{1}^{i}\right)+\ldots+\alpha_{m} I_{m}\left(x_{m}^{i}\right)+\varepsilon^{i},
$$

where the error term $\varepsilon^{i}$ captures idiosyncratic individual factors that may influence the individual valuation of life satisfaction. Schokkaert (2007) argues that these should be ignored in the computation of individual-specific valuations. He writes "On the one hand, the robust statistical relationship between functionings and life satisfaction may provide useful information on the relative weights to be given to the various dimensions in the calculation of individual living standards. On the other hand, from a non-welfarist point of view we do not want idiosyncratic individual factors to wipe out the effects of conditions of material deprivation, linked, for example, to unemployment or job satisfaction" (Schokkaert 2007, p.423). This leads to the following measure of well-being $I$ :

$$
I(x)=\alpha_{1} I_{1}\left(x_{1}\right)+\ldots+\alpha_{m} I_{m}\left(x_{m}\right) .
$$

This measure is similar to the one described by equation (2) and assumes the degree of substitutability, $\beta$, to be equal to 1 . Regression techniques allow sophistications of the above regression model (4). First, the results can be controlled or cleaned for some variables that affect the subjective satisfaction levels, but that should not affect the computed well-being -religious beliefs, for instance. Second, one can take into account the ordinal nature of the self-reported life satisfaction by using a multinomial model, instead of a standard linear model (see, Ferrer-i-Carbonell and Frijters (2004)). Third, one can correct for individual traits when working on a panel data set. Finally, it might be interesting to allow for heterogeneity in weights by including interaction terms with demographic variables. Indeed, it has been argued before that the weights constitute 
value judgements about the good life and it is widely documented that there is a much inter-personal variation in these value judgements. Examples of these proposals are by Fleurbaey et al. (2009) who investigate Russian well-being and by Schokkaert et al. (2009) who look at the measurement of job quality.

In general, regression based weights have the drawback that they need an appropriate variable $Y^{i}$, which might not always be available. Furthermore, when the included dimensions of well-being are highly correlated, the estimated coefficients of $\alpha_{j}$ will be estimated in an imprecise way. The standard errors might be too large, which is problematic if the researcher chooses whether or not to include the dimension, depending on its significance. In addition, multicollinearity might hamper the interpretation of estimated coefficients as relative importance of the dimensions to overall well-being, as the estimates do not allow for the disentanglement of the effect of an explanatory variable, independent of the others to which this is related. ${ }^{17}$ Finally, one has to make the difficult (normative) decision about which variables to treat as dimensions of well-being and which as exogenous control variables.

\section{Beyond a unique weighting scheme}

So far, we looked at approaches that evaluate the well-being of an individual or country by a unique well-being index $I($.$) that is specified by expression (1) for a specific set of$ parameters. These approaches have the advantage that they lead to a complete ordering of the achievement vectors, in other words, that all possible achievement vectors can be ordered. Yet, it requires agreement on the functional form and a unique set of parameters, in particular on the most appropriate weights. Such an agreement might be hard to reach and not even necessary (Sen 2009). Therefore, we look at two alternative approaches leading to incomplete orderings of the achievement vectors.

The robustness analysis approach allows for some degree of agnosticism on the weights, and looks at specific ranges of weights for which there is unanimity in results over the class of well-being indices obtained by expression (1). Nonetheless, this agnosticism comes at a price: an approach based on ranges of weights, leads to incomplete orderings of the achievement vectors. How incomplete the ordering becomes, or how many achievement vectors will become incomparable, depends on the allowed width of the ranges and the correlation between the achievements of the individuals across the dimensions. Foster et al. (2009) show that the stronger the correlation between the dimensions, the less important the exact specification of the weights becomes to rank all achievement vectors. The authors propose a test to set weights that rank (a group of) countries in a robust way. Decancq and Ooghe (forthcoming) propose a normative framework to carry out sensitivity analyses for all possible weighting schemes and, thus,

${ }^{17}$ On the other hand, multicollinearity does not bias the results and, in particular, the reliability of the prediction of overall well-being for each individual. 
identify the range of weighting schemes that leads to robust results. Finally, a report from Statistics Sweden (2004) compares the different rankings of countries obtained using a large set of randomly chosen weighting schemes. The results are then presented as proportions of weighting schemes by which a country has been ranked first, second, and so on.

Dominance analysis represents a second approach. This alternative goes one step further away from uniqueness and assumes that it is not only impossible to reach an agreement on the weighting scheme, but also on the functional form used to aggregate the dimensions. The main idea is that, at most, we can reach a consensus on a very minimal set of properties, based on the (partial) derivatives of the well-being index. Most often this leads to incomplete orderings of the achievement vectors. This area was pioneered by Atkinson and Bourguignon (1982), then extended by Muller and Trannoy (2004) for comparisons of three-dimensional well-being distributions and by Duclos et al. (2006) for multidimensional poverty comparisons.

Although it is clear that these two alternative approaches can never answer the question on how to select the most appropriate unique weighting scheme, they might give an idea how important the choice of the weighting scheme is for the obtained results and how much room there is for agnosticism, concerning the weights. In general, some type of sensitivity analysis for alternative weighting schemes can be very helpful in determining how robust the well-being index and the implied ordering of the achievement vectors is for alternative choices.

\section{Conclusion}

In this paper, we surveyed different approaches for setting weights in multidimensional indices. We provided a general framework where most methods fit in. This framework allowed us to understand the meaning of weights as crucial factors determining the trade-off between dimensions. Dimension-weights are, however, not the only component determining this trade-off. The form of the transformation of the original variables into commensurable units and the parameter of substitution between dimensions also play an important role. However, these components are more often than not ignored in the literature.

We reviewed eight approaches used to set dimension weights, highlighting their advantages and drawbacks. Thereby we distinguished three categories of approaches: data-driven, normative and hybrid approaches. These approaches use information which is very different in nature and may lead to quite different weighting schemes. Ultimately, the definite test for any weighting scheme should be in terms of its reasonability in terms of implied trade-offs between the dimensions. As long as there is no widely accepted theoretical framework on how to set these trade-offs, the researcher has no choice than to rely on her common sense and to be very cautious in interpreting the obtained orderings of 
the achievement vectors. In all cases, robustness tests and a sensitivity analysis should be called upon to determine whether results are solely driven by the specific value of weights selected. 


\section{References}

Anand, S., And A. K. Sen (1997): "Concepts of human development and poverty: A multidimensional perspective," Human development papers, Human Development Report Office (UNDP), New York.

Arrow, K. (1950): "A difficulty in the concept of social welfare," Journal of Political Economy, 58(4), 328-346.

Atkinson, A. B., And F. Bourguignon (1982): "The comparison of multidimensioned distributions of economic status," Review of Economic Studies, 49(2), 183-201.

Battiston, D., G. Cruces, L. F. Lopez-Calva, M. A. Lugo, and M. E. SanTOS (2009): "Income and beyond: Multidimensional poverty in six Latin American countries," ECINEQ Working Paper 142.

Becker, G. S., T. J. Philipson, and R. R. Soares (2005): "The quantity and quality of life and the evolution of world inequality," American Economic Review, 95(1), 277-291.

Becker, R. A., L. Denby, R. McGill, and A. R. Wilks (1987): "Analysis of data from the places rated almanac," The American Statistician, 41(3), 169-186.

Blackorby, C., and D. Donaldson (1982): "Ratio-scale and translation-scale full interpersonal comparability without domain restrictions: Admissible social-evaluation functions," International Economic Review, 23(2), 249-68.

Boelhouwer, J. (2002): "Quality of life and living conditions in The Netherlands," Social Indicators Research, 60(1-3), 89-113.

Bossert, W., S. Chakravarty, and C. D’Ambrosio (2009): "Multidimensional poverty and material deprivation," ECINEQ Working Paper 129.

Bourguignon, F. (1999): "Comment on "Multidimensioned approaches to welfare analysis' by E. Maasoumi," in Handbook of income inequality measurement, ed. by J. Silber, pp. 477-84. Kluwer Academic, London.

Bourguignon, F., and S. R. Chakravarty (2003): "The measurement of multidimensional poverty," Journal of Economic Inequality, 1(1), 25-49.

Brandolini, A. (2007): "On synthetic indices of multidimensional well-being: Health and income inequalities in France, Germany, Italy, and the United Kingdom," Bank of Italy, Economic Research Department 668. 
CARD, D. (1999): "The causal effect of education on earnings," in The Handbook of Labor Economics, ed. by O. Ashenfelter, and D. Card, vol. III. North Holland, Amsterdam.

[Center for Global Development] Birdsall, N., and D. Roodman (2003): "The Commitment to Development Index: A scorecard of rich-country policies," Center for Global Development, Washington, DC.

Cerioli, A., and S. Zani (1990): "A fuzzy approach to the measurement of poverty," in Income and Wealth Distribution, Inequality and Poverty, ed. by C. Dagum, and M. Zenga. Springer-Verlag, Berlin.

Cheli, B., And A. Lemmi (1995): "A totally fuzzy and relative approach to the multidimensional analysis of poverty," Economic Notes, 24, 115 - 134.

Cherchye, L., C. K. Lovell, W. Moesen, and T. Van Puyenbroeck (2007): "One market, one number? A composite indicator assessment of EU internal market dynamics," European Economic Review, 51(3), 749 - 779.

Cherchye, L., W. Moesen, N. Rogge, and T. Van Puyenbroeck (2007): "An Introduction to "Benefit of the Doubt" Composite Indicators," Social Indicators Research, 82(1), $111-145$.

Cherchye, L., W. Moesen, N. Rogge, T. Van Puyenbroeck, M. Saisana, Saltelli, R. Liska, and S. Tarantola (2008): "Creating composite indicators with DEA and robustness analysis: The case of the technology achievement index," Journal of the Operational Research Society, 59(2), 239 - 251.

Chowdhury, S., and L. Squire (2006): "Setting weights for aggregate indices: An application to the commitment to development index and human development index," Journal of Development Studies, 42(5), 761-771.

[Community and local Government] Noble, M., D. Mclennan, K. Wilkinson, A. Whitworth, H. Barnes, and C. Dibben (2008): "The English Indices of Deprivation 2007," Communities and Local Government, London.

de Kruijk, H., and M. Rutten (2007): "Weighting dimensions of poverty based on people's priorities: Constructing a composite poverty index for the Maldives," QSquared Working Paper 35, Centre For International Studies, University of Toronto.

Decancq, K., A. Decoster, and E. Schokkaert (2009): "The evolution of world inequality in well-being," World Development, 30(1), 11-25.

Decancq, K., and M. A. Lugo (2009): "Measuring inequality of well-being with a correlation-sensitive multidimensional Gini index," ECINEQ Working Paper 124. 
Decancq, K., and E. Ooghe (forthcoming): "Has the world moved forward? A robust multidimensional evaluation," Economics Letters.

Desai, M. (1993): "Income and alternative measures of well-being," in Monitoring social progress in the 1990s, ed. by D. Westendorff, and D. Ghai, pp. 23-39. Aldershot, Avebury.

Desai, M., And A. Shah (1988): "An econometric approach to the measurement of poverty," Oxford Economic Papers, 40, 505-522.

Despotis, D. K. (2005a): "Measuring human development via data envelopment analysis: The case of Asia and the Pacific," Omega, pp. 385-390.

(2005b): "A reassessment of the Human Development Index via data envelopment analysis," Journal of the Operational Research Society, 56(8), 969-980.

Deutsch, J., And J. Silber (2005): "Measuring multidimensional poverty: An empirical comparison of various approaches," Review of Income and Wealth, 51(1), 145-74.

Di Tommaso, M. L. (2006): "Measuring the well being of children using a capability approach: An application to Indian data," CHILD - Centre for Household, Income, Labour and Demographic economics, CHILD Working Paper 05.

Diener, E., And E. Suh (1997): "Measuring quality of life: Economic, social and subjective indicators," Social Indicators Research, 40, 189-216.

Duclos, J.-Y., D. E. Sahn, and S. D. Younger (2006): "Robust multidimensional poverty comparisons," Economic Journal, 116(514), 943-968.

Ebert, U., And H. Welsch (2004): "Meaningful environmental indices: A social choice approach," Journal of Environmental Economics and Management, 47(2), 270-283.

Ferrer-i Carbonell, A., and P. Frijters (2004): "How important is methodology for the estimates of the determinants of happiness?," Economic Journal, 114(497), 641-659.

Fleurbaey, M. (2009): "Beyond GDP: the quest for a measure of social welfare," Journal of Economic Literature, 47(4), 1029-1075.

Fleurbaey, M., and G. Gaulier (2009): "International comparisons of living standards by equivalent incomes," Scandinavian Journal of Economics, 111(3), 597-624.

Fleurbaey, M., E. Schokkaert, and K. Decancq (2009): "What good is happiness?," CORE discussion paper 2009/17. 
Foster, J., L. F. Lopez-Calva, and M. Szekely (2005): "Measuring the distribution of human development: Methodology and an application to Mexico," Journal of Human Development, 6(1), 5-25.

Foster, J., M. McGillivray, and S. Seth (2009): "Rank robustness of multidimensional well-being measures," OPHI Working Paper 26.

Foster, J., And A. K. Sen (1997): On Economic Inequality. Oxford University Press, Oxford.

Fusco, A., And P. Dickens (2008): "The Rasch model and multidimensional poverty measurement," in Quantitative Approaches to Multidimensional Poverty Measurement, ed. by N. Kakwani, and J. Silber. Palgrave-MacMillan.

Guio, A.-C., A. Fusco, And E. Marlier (2009): "A European Union approach to material deprivation using EU-SILC and Eurobarometer data," IRISS Working Papers 2009-19.

HALLERÖD, B. (1995): "The truly poor: direct and indirect consensual measurement of poverty in Sweden," Journal of European Social Policy, 5, 111-129.

(1996): "Deprivation and poverty: A comparative analysis of Sweden and Great Britain," Acta Sociologica, 39(2), 141-168.

Hirschberg, J. G., E. MaAsoumi, and D. Slottje (1991): "Cluster analysis for measuring welfare and quality of life across countries," Journal of Econometrics, 50(12), $131-150$.

Hume, D. (1740): A Treatise of Human Nature. Penguin Books, reprinted in 1985, London.

Jacobs, R., P. Smith, and M. Goddard (2004): "Measuring performance: An examination of composite performance indicators," CHE Technical Paper Series 29, Centre for Health Economics, University of York.

Justino, P. (2005): "Empirical applications of multidimensional inequality analysis," Poverty Research Unit at Sussex PRUS Working Paper 23, Department of Economics, University of Sussex.

Kahneman, D., and A. B. Krueger (2006): "Developments in the measurements of subjective well-being," Journal of Economic Perspectives, 20(1), 3-24.

Klasen, S. (2000): "Measuring poverty and deprivation in South Africa," Review of Income and Wealth, 46, 33-58. 
Krishnakumar, J. (2007): "Going beyond functionings to capabilities: An econometric model to explain and estimate capabilities," Journal of Human Development, 7(1), 39 63.

Krishnakumar, J., and P. Ballon (2008): "Estimating basic capabilities: A structural equation model approach applied to Bolivian data," World Development, 36(6).

Krishnakumar, J., and A. Nadar (2008): "On exact statistical properties of multidimensional indices based on principal components, factor analysis, MIMIC and structural equation models," Social Indicators Research, 86(3), 481-496.

Kuklys, W. (2005): Amartya SenŠs Capability Approach: Theoretical Insights and Empirical Applications. Springer, Berlin.

Lugo, M. A. (2007): "Comparing multidimensional indices of inequality: methods and application," Research on Economic Inequality, 14, 213-236.

MaAsoumi, E. (1986): "The measurement and decomposition of multi-dimensional inequality," Econometrica, 54(4), 991-97.

MaAsoumi, E., And M. A. Lugo (2008): "The information basis of multivariate poverty assessments," in Quantitative Approaches to Multidimensional Poverty Measurement, ed. by N. Kakwani, and J. Silber. Palgrave-MacMillan.

Maasoumi, E., and G. Nickelsburg (1988): "Multidimensional measures of wellbeing and an analysis of inequality in the Michigan data," Journal of Business and Economic Statistics, 6(3), 327-334.

Mack, J., And S. Lansley (1985): Poor Britain. Routledge.

Mahlberg, B., and M. Obersteiner (2001): "Remeasuring the HDI by data envelopment analysis," Interim report IR-01-069, International Institute for Applied System Analysis.

Mascherini, M., and B. Hoskins (2008): "Retrieving expert opinion on weights for the Active Citizenship Composite Indicator," European Commission, Joint Research Centre, Institute for the Protection and Security of the Citizen.

Mayer, S. E., And C. Jencks (1989): "Poverty and the distribution of material hardship," Journal of Human Resources, 24(1), 88-114.

Melyn, W., And W. Moesen (1991): "Towards a synthetic indicator of macroeconomic performance: Unequal weighting when limited information is available," Katholieke Universiteit Leuven, Public Economic Working Paper 17.

Micklewright, J. (2001): "Should the UK government measure poverty and social exclusion with a composite index?," CASE Report 13, LSE. 
Moldan, B., and S. Billharz (1997): Indicators of Sustainable Development. John Wiley, Chichester.

Muller, C., And A. Trannoy (2004): "A dominance approach to well-being inequality across countries," IDEP Working Paper 313, Institut d'economie publique (IDEP), Marseille, France.

Murphy, K. M., and R. H. Topel (2006): "The value of health and longevity," Journal of Political Economy, 114, 871-904.

Narayan, D. (2000): Voices of the Poor: Can Anyone Hear Us? World Bank Publication, DC.

Nardo, M., M. Saisana, A. Saltelli, and S. Taranto (2005): "Tools for composite indicators building," EUR 21682 EN, European Communities.

Nardo, M., M. Saisana, A. Saltelli, S. Tarantola, A. Hoffman, and E. GioVANNINI (2005): "Handbook on constructing composite indicators: Methodology and user guide," OECD Statistical Working Paper STD/DOC(2005)3.

Nilsson, T. (2010): "Health, wealth and wisdom: Exploring multidimensionsl inequality in a developing country," Social Indicators Research, 95(2), 299-323.

Noble, M., G. Wright, G. Smith, and C. Dibben (2006): "Measuring multiple deprivation at the small-area level," Environment and Planning, 38(1), 169-185.

Noorbakhsh, F. (1998): "The Human Development Index: Some technical issues and alternative indices," Journal of International Development, 10, 589-605.

Nussbaum, M. (2000): Women and Human Development. Cambridge University Press, Cambridge.

Osberg, L., and A. Sharpe (2002): "An index of economic well-being for selected OECD countries," Review of Income and Wealth, 48(3), 291-316.

Popper, K. (1948): "What can logic do for philosophy? Logical postivism and ethics," in The symposia read at the joint session of the Aristotelian Society and the Mind Association at Durham, July 9-11, pp. 141-154, London. Harrison and Sons.

RAM, R. (1982): "Composite indices of physical quality of life, basic needs fulfilment, and income: A principal component representation," Journal of Development Economics, $11(2), 227-247$.

Ramos, X., and J. Silber (2005): "On the application of efficiency analysis to the study of the dimensions of human development," Review of Income and Wealth, 51(2), 285-309. 
Ravallion, M. (1997): "Good and bad growth: The human development reports," World Development, 25(5), 631-638.

Rawls, J. (1971): A Theory of Justice. Belknap Press of Harvard University Press, Cambridge, Mass.

SAATY, R. W. (1987): "The analytic hierarchy process- what it is and how it is used," Mathematical Modelling, 9, 161-176.

Save the Children, (2000): "State of the World's mothers 2000," Save the Children, Connecticut.

Schokkaert, E. (2007): "Capabilities and satisfaction with life," Journal of Human Development, 8(5), 415-430.

Schokkaert, E., L. Van Ootegem, and E. Verhofstadt (2009): "Measuring job quality and job satisfaction," FEB working paper 2009/620.

Sen, A. K. (1985): Commodities and capabilities. North-Holland, Amsterdam and Oxford.

(2009): The Idea of Justice. Allen-Lane.

Somarriba, N., and B. Pena (2009): "Synthetic indicators of quality of life in Europe," Social Indicators Research, 94, 115-133.

SRinivasan, T. N. (1994): "Human development: A new paradigm or reinvention of the wheel?," American Economic Review, 84(2), 238-43.

[Statistics Sweden] Hagèn, H.-O. (2004): "Comparing welfare of nations," Background Facts on Economic Statistics 2004:15, Department of Economic Statistics, Statistics Sweden.

Stiglitz, J. E., A. Sen, And J.-P. Fitoussi (2009): "Report by the Commission on the measurement of economic performance and social progress," Commission on the Measurement of Economic Performance and Social Progress, mimeo.

Townsend, P., P. Phillimore, and A. Beattie (1988): Health and deprivation: Inequality and the North. Routledge, London.

United Nations Development Programme, (2005): "Human Development Report 2005," Oxford University Press, New York.

(2007): "Human Development Report 2007/2008. Technical note," Oxford University Press, New York. 
VAn den Bosch, K. (1998): "Perceptions of the minimum standard of living in Belgium: Is there a consensus?," in Empirical Poverty Research in a comparative Perspective, ed. by H. AndreSS. Ashgate, Aldershot.

Walzer, M. (1983): Spheres of Justice: A Defense of Pluralism and Equality. Basic Books, New York.

World ECONOMic Forum (2001): "2001 Environmental sustainability index," World Economic Forum and Yale Center for Environmental Law and Policy and Center for International Earth Science Information Network, Davos.

Zaim, O., R. Fare, and S. Grosskopf (2001): "An economic approach to achievement and improvemnt indexes," Social Indicators Research, 56, 91 Ü118.

Zhou, P., B. W. Ang, And D. Q. Zhou (2010): "Weighting and aggregation in composite indicator construction: A multiplicative optimization approach," Social Indicators Research, 96(1), 169-181. 